\title{
CULTURAL LANDSCAPE, FLOODS AND REMOTE SENSING
}

\author{
Dušan Húska', L'uboš Jurík², Lucia Tátošová ${ }^{3}$ Karol Šinka³ , Johana Jakabovičováa
}

1 Faculty of European Studies and Regional Development, Department of Regional Bioenergetics, Slovak University of Agriculture in Nitra, Trieda Andreja Hlinku 2, 94976 Nitra, Slovakia, e-mail: dusanhuska@ gmail.com

${ }^{2}$ Faculty of Horticulture and Landscape Enegineering. Department of Water Resources and Environmental Engineering, Slovak University of Agriculture in Nitra, Trieda Andreja Hlinku 2, 94976 Nitra, Slovakia

${ }^{3}$ Faculty of Horticulture and Landscape Enegineering. Department of Landscape Planning and Land Consolidation, Slovak University of Agriculture in Nitra, Trieda Andreja Hlinku 2, 94976 Nitra, Slovakia

${ }^{4}$ Faculty of Economics, Department of Languages, Slovak University of Agriculture in Nitra, Trieda Andreja Hlinku 2, 94976 Nitra, Slovakia

Received: 2017.02 .16

Accepted: 2017.03.07

Published: 2017.05 .02

\begin{abstract}
The dynamics of the cultural landscape is associated with the penetration of people into the natural landscape, the settling and adaptation to the needs of the society and its development. Climate creates the decisive influence, specifically the form of extremely high rainfall causing flooding. Adverse impact on the cultural agricultural landscape is mainly the submersion time. This time depends on the configuration of the terrain, its disposition and the existing drainage ditches in the area, ensuring the drainage of the flood to the recipients. Long-lasting floods have stipulated taking measures for the protection of the area from flooding by building dikes and drainage of the flood from the area. Identifying the extent of extreme floods and zones of permanent waterlogging is currently provided by modern technology which allows recording satellite images in different spectral bands. Within the basic distinguishing signs mainly accruing is used and it is possible to track changes of the extent of flooded areas and thus identify problem areas insufficiently protected against long-term flooding. Consequently, it is possible to solve the concept of exploiting such areas to keep them in the structure of PPF or their reclassification in wetland systems with necessary legislative security. The aim of this paper is to show the possibility of using satellite images in identifying the extent of flooding.
\end{abstract}

Keywords: drainage, flood, landscape, river, satellite

\section{INTRODUCTION}

Dynamic development of the weather on Earth in the recent period has been characterized by the onset of extreme situations resulting in floods. As a result of torrential rains that may cause spilling the river water from the river bed, or may flood lowland areas due to surface runoff from the surrounding area. The result of these phenomena is areas flooded with water. The overflow time can be diametrically different. In case of shedding the dykes, water from flooded areas gradually returns to the riverbed. Return of water to the river depends on the existence of the system of drainage of internal waters. Surface water is concentrated in the drainage channels and via their networks it gets to the recipient and allows the entry to the previously flooded land. The functional drainage systems are able to provide draining of excess water in the course of 2-3 weeks, as required by the technical Standard to ensure water drainage [Ministry of Environment 2011].

Evaluation of the functioning of drainage systems currently provides the remote sensing system that can provide information about spatial and time course of flooded areas. The paper deals with the evaluation of satellite images from the period of extraordinary flooding in the area of Brodog Hornád in 2010 [Holičová 2013, WFD 2007/60 EU 2011, Ministry of Environment 2011]. 


\section{METHODOLOGY}

Conditions for draining excess water from the territory were determined by the technical Standards for draining agricultural land. Drainage systems have to create conditions for ensuring the correct functioning of the water regime. Management of drainage system was under the jurisdiction of the State Land Drainage System Administration and land drainage cooperatives or Water Management Enterprises. Their competence is monitoring, maintenance and repairing of drainage systems.

Currently, there are prevailing views about the harmfulness of drainage systems and in general it is argued that the drainage systems cause drying of soil. In compliance with the technical Standards, regulation of the water regime was optimal and secured mainly draining of the excess water causing waterlogging of agricultural land. It should be realized that the cultural landscape was created primarily to support human development, exploit the country to the benefit of the population as well as to provide necessary food resources. Regulation of soil water regime in the plains was carried out by maintaining the water level in the drainage systems with the help of pumping stations. In case of floods or excess water they had to drain the water into recipients [Holičová 2013].

Today we have modern methods to monitor the extent of flooded areas using remote sensing. In practice, the CORINA system is commonly used and allows you to track the way how land resources are used. Remote sensing also provides more possibilities for evaluating the coverage of the surface under different conditions. Particularly, monitoring the water coverage area by recording the reflection of the land surface in the zone outside the visible spectrum is preferred, especially in the zone of infrared radiation. Infrared radiation is largely absorbed by water and thus reflection of surface covered with water is close to zero.

A new approach for solving complex flood protection and securing the environment for people represents Magdalini [Magdalini 2015] in the assessment of water management in the Netherlands. The principle should solve the dilemma, "What do we have to sacrifice first? Environment? economy? or people? This question was already answered by our ancestors, when they began to solve the protection of persons and their property. Even today, we must seek a comprehensive solution [WFD 2007/60 2011, Ministry of Environment 2011, Ministry of Agriculture 2011].

\section{RESULTS}

In the period from 1950 to 1985 the Eastern Slovak Lowland (VSN) was protected against the long-term soaking by water drainage systems, covering the total area of 480000 hectares $(20 \%$ PPF). The drainage system consisted of systematic tube drainage, outfall drains into waterways gravity and in parts of the area with a small slope drains were built with pumping stations, permitting penetration of water from the flood even in case of high water level in the stream. These systems included $6282 \mathrm{~km}$ of canal network, 41 pumping stations, 458000 hectares of systematic drainage and 491 gas stations. Over the last 25 years there was not significant concern about these systems and their functionality. Based on the survey in 1999 [Húska and Jurík 2000, Kabina and Jurík 1999] much of the drains were clogged with suspended load and overgrown with aquatic plants and grass. Runoff drains were broken, drainage outlets destroyed and drainage shafts buried with garbage [Annual Report 2011]

According to a survey of the Technical University in Zvolen [Technical university Zvolen 2011], the situation of the water management facilities can be compared by looking at the aerial photographs of the territory in 1950.

In Figure 1 you can see extensive wetlands in the area of the current Širava water reservoir.

VSN is an area made up mostly of heavy soils with a very low coefficient of filtration. VSN is a large flat area where the altitude is around 100 to 150 meters above the sea level. VSN is interwoven with many rivers. The most important are Ondava, Topl'a, Laborec and Latorica which flow near the border with Hungary into the river Bodrog. VSN climate is warm. In winter months the temperature falls down between -2 to $-4{ }^{\circ} \mathrm{C}$, in the summer months between $17-20{ }^{\circ} \mathrm{C}$ on average. The number of days with snow cover ranges from 50 to 70 and the number of summer days is 50 to 70 [https://sk.wikipedia.org/].

Due to the intense rainfall flood situations occur frequently during which a large part, especially the southern areas are usually flooded. Protection of the whole area is impossible. The solution can be found in new approaches "creating space for the river" looking for the appropriate measures to deal with the large flows in rivers. Another problem is cross-border flows and international agreements on the allowable amount of water discharged into the partner country. These limits are forcing the management to reduce the flow of 


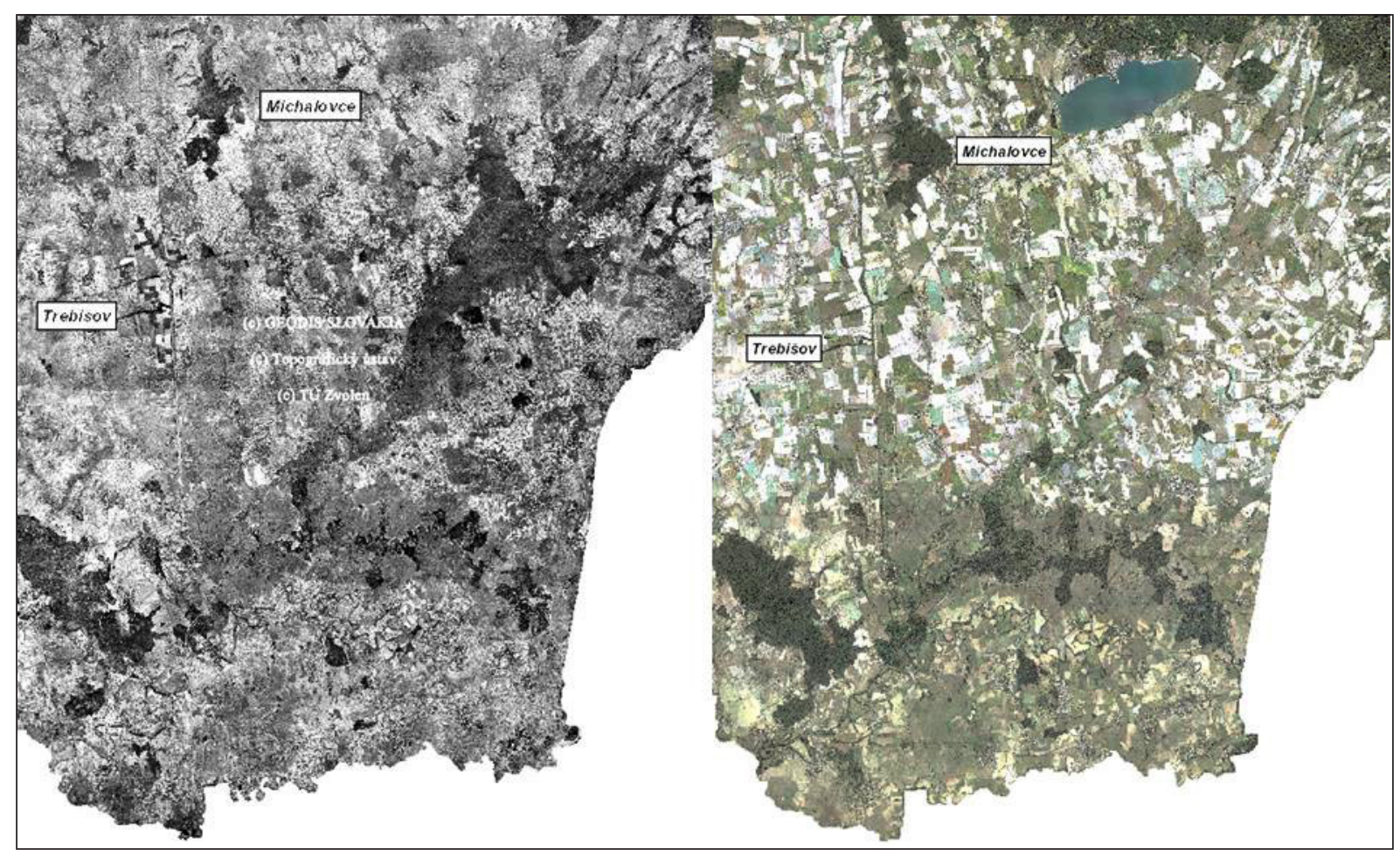

Figure 1. Aerial photos of the VSN area in 1950 and 2010 [http://mapy.tuzvo.sk/HOFM]

streams in the border region, especially by flooding of adjacent areas of flows on the Slovak side.

In the past this area was mainly the marshes and wetlands with their adverse effects on the environment. Drainage systems improved the conditions of life of people but reduced the retention capacity for water in that area. Currently, revitalization and restoration of wetlands and marshes could be considered but the major problem is land ownership. Revitalization of the former country would require resolving the question of financial compensation to landowners in response to

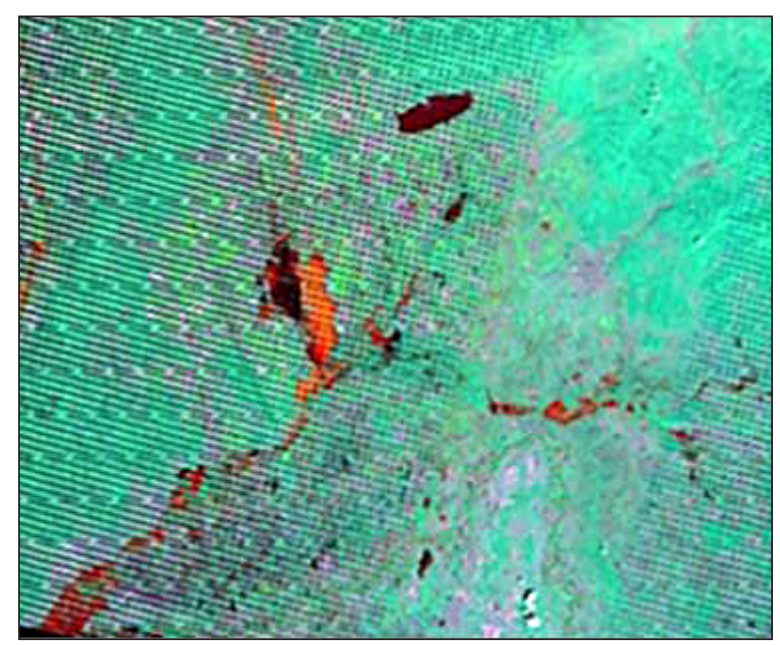

Figure 2. VSN flooded areas during the flood 06/06/2010 (red parts) LANDSAT [VSN 2010] changes in agricultural land use for permanent or temporary grassland and lakes.

It would be appropriate to use information on the achieved production in the affected area and if the owner would agree with the change of use, the difference between the yields would be the subject of compensation for the reduction in the potential yield on the ground. In the long term the economic losses were outweighed by losses from flood risks. The government should accede to such a solution, which would contribute to the overall positive hydrological balance of Slovakia.

Aatellite images of Landsat show the consequences of floods in May 2010 where you can see the flooded areas along streams in the VSN.

The biggest problem with runoff is in the southern part of the VSN, which is drained by the channel Somotor (Fig. 3). The channel diverts water from the large flat area, which has a slight slope from the east to the west. At the channel length of $21 \mathrm{~km}$ the altitude difference is only $5 \mathrm{~m}$. Therefore, the slope of the area is only 0.000238 . Particularly problematic is the flow profile that is largely overgrown and clogged with sediments floated from the surrounding land. Channeling water at high water levels in the river provide drainage pumping stations which, however, have little activity since the pump capacity exceeds the 


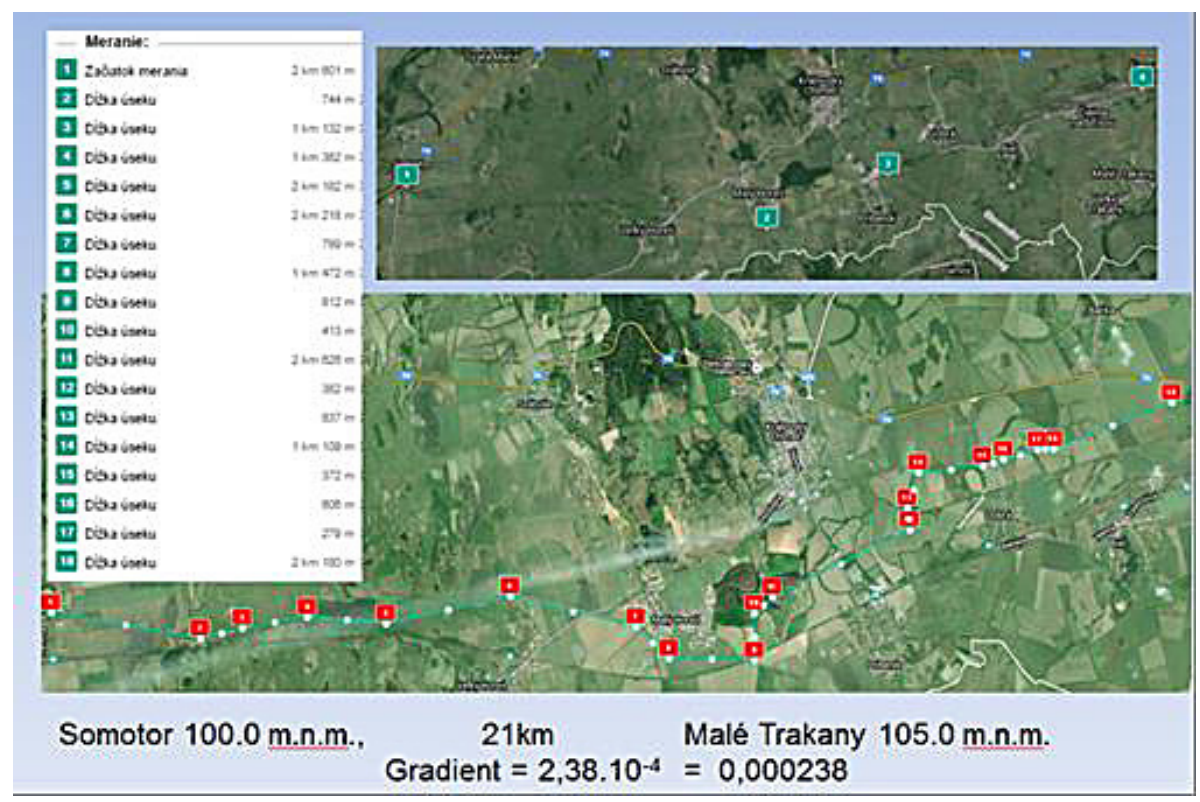

Figure 3. Channel Somotor (Google Map)

potential flow of water through the channel, and flow-channel area is not able to transport such amounts of water to which the filling station is designed. [Kotorová, Kováč 2013].

The situation is similar in Western Slovakia in the river basin of Žitava (Figs. 4 and 5).

In the late May and early June in 2010 abundant rainfall in the basin Žitava caused the outpouring of water from the stream channel, and a flow of Q1000 was recorded. The attached photos show the flooded area near the village of Maňa [Flood 2010].

Floods at that time did not have tragic consequences in terms of human victims. However, the impact lasted for a long period of time. In Slovakia, neglecting regular maintenance of drainage network resulted in a slow return of water from the flooded area to the water flows. Long lasting flooded areas cause irreversible damage to vegetation, damage of soil structure and reproduction of mosquitoes. Discussing a comprehensive approach in addressing the issues of regulation of soil water regime all these factors must be taken into consideration. There are several options to solve the problem. Complete reconstruction and repair of existing drainage systems that ensure agricultural production or in the territories critically threatened by flooding change the form of land resources exploitation by converting them into bodies of water or use a combination of both approaches.

The extent of flooded areas and a gradual decline of flooded areas can be monitored by us- ing satellite imagery in particular in the infrared range or on the radar picture. The areas that are waterlogged in the long term could be used to build polders - polders are already known in the VSN (polder Beša). In case of threat of high water level to the area it would be possible to use these polders for water storage by transferring it to the reception area through drainage channels, thus avoiding damage to dykes when they spill through the flood wave. Retrospective satellite images could determine critical water levels in the floods. The floodgates would open and the water would gradually spill on adjacent areas.

Flood condition, including the protection of the territory requires detailed monitoring. In this context it is possible to use extensive benefits of remote sensing where we start from the resolution of satellite images. In this respect we consider the following forms of resolutions:

- Spectral resolution is defined in the range of wavelengths (the electromagnetic spectrum) and the number of intervals of the sensor (VIS, IR, NIR, radar)

- Geometric resolution refers to the ability of the satellite sensor to effectively record part of the Earth's surface within a pixel (30x30 m Landsat, MODIS 1x1 km, 250x250 m)

- Radiometric resolution is defined as the ability of the imaging system to record many levels of brightness (the number of shades of gray) usually used record 8-bit (0-255), 11-bit (0-2047), 12-bit (0-4095) or 16-bit (0-65535). 


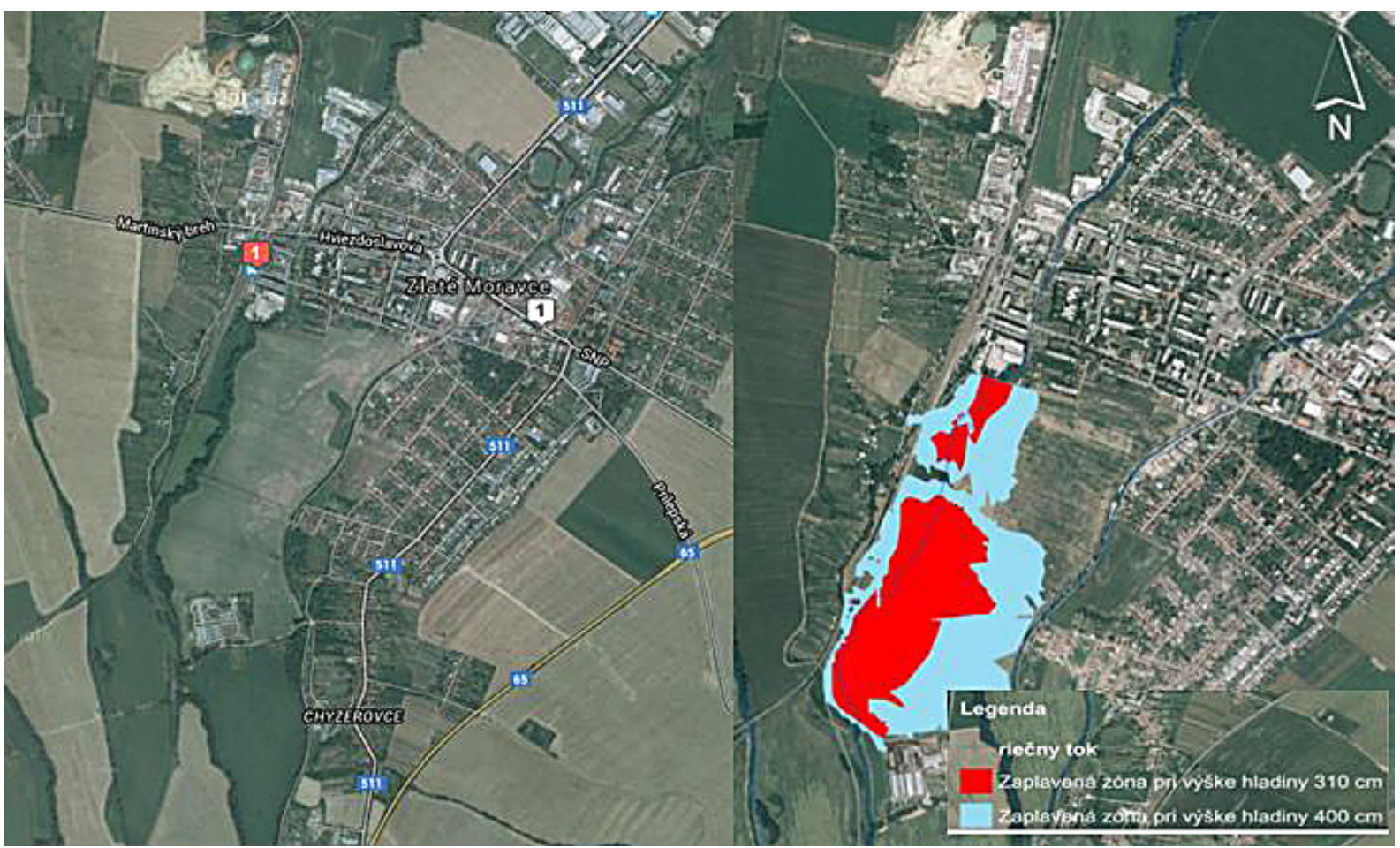

Figure 4. Flooded agricultural land in the region Zlaté Moravce with the water level 310 and $400 \mathrm{~cm}$ (Simulation) [Zorád 2010].
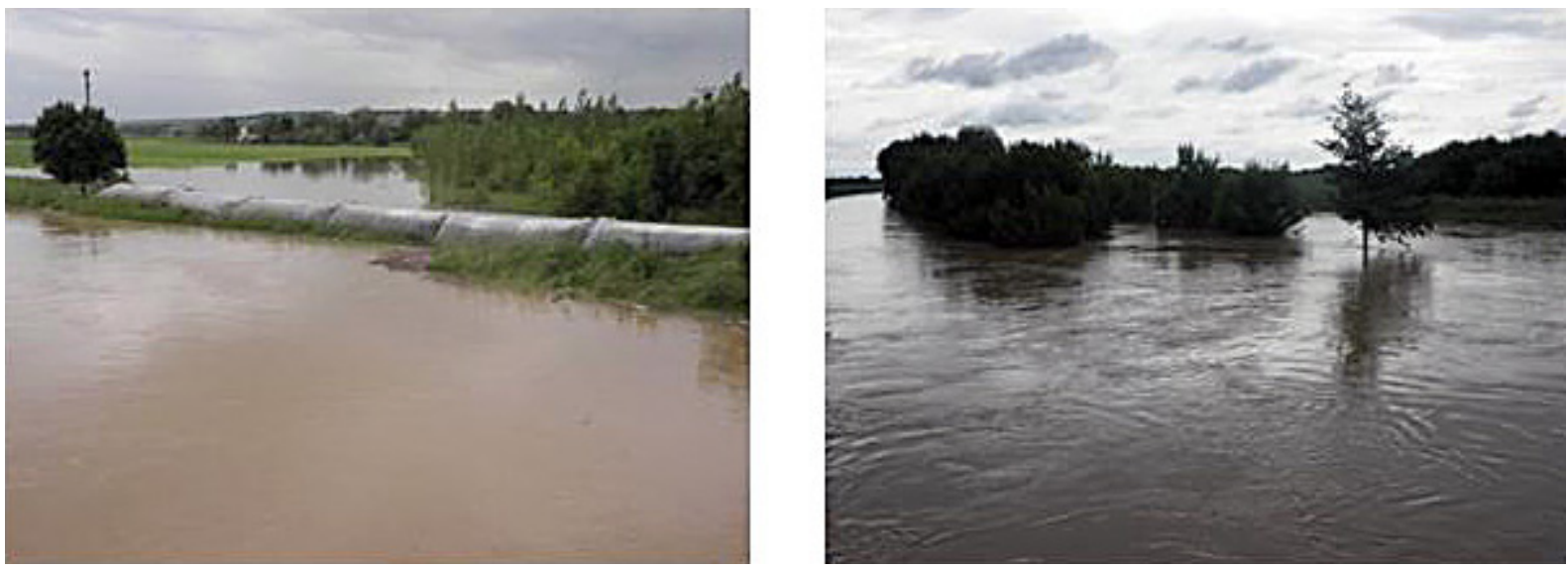

Figure 5. Farmland flooded during floods on Žitava, 2010 (Photo by D. Húska)

- Time resolution is defined by the time interval (for example, days), which will take place between the period of the image surface at a particular location [Mateeul et al. 2012].

Thus, we can choose a suitable distinctive feature and record it retrospectively especially regarding time changes. To select the appropriate image, we can use a web browser that provides various show times of satellite images of any area on Earth. Suitability for image analysis of satellite imagery areas called "image hunter, Apollo mapping [Satellite images 2016]" can be opened via websites.
On the basis of the monitoring period it is possible to determine the areas that are not adequately protected in terms of draining excessive water, on the basis of which it would be possible to decide on a possible change of land use.

\section{CONCLUSIONS}

Floods occur due to the extreme weather events and especially due to the high amount of rainfall in a short period of time resulting in longer periods of flooding of lowland areas in southern Slovakia. Critically flooded areas can be iden- 
tified by using satellite imagery. Such a change of land use would require registering the position of the territory in the cadaster PPF. It would be necessary to resolve the legislative issues related to ownership of the parcel of land and the subsequent legislative process of owners compensation for the change of land use in accordance with social interests. Such measures could be carried out in compliance with the European Water Directive, which aims to achieve a better status of water bodies. Basic methods to identify areas that could be included in the draft amendments of PPF use are as follows:

- Monitoring the progressive reduction of the water level in the flooded areas by satellite.

- Monitoring the functionality of drainage systems in the flooded area,

- Proposed reconstruction system for the regulation of water regime in flooded areas

- Design and construction of new regulatory elements (buildings) needed to ensure the soil water regime using the polders or permanent wetlands.

- Implementation of the measures proposed.

\section{Acknowledgements}

The article was elaborated with the support of the project "Anthropogenic impact on the production and quality of surface runoff from small watersheds in the conditions of climate change", from the Grant Agency VEGA 1/0949/11 in program "Creation and quality of surface runoff from small watersheds in the conditions of climate change".

\section{REFERENCES}

1. Annual Report 2011: Annual Report 2010, Regional Environmental Office Košice

2. Basso B., Cammarano D., De Vita P., 2004: Remotely sensed vegetation indices: Theory and Applications for crop management. Rivista Italiana di Agrometeorologie 36-53 (1).

3. Blaas G., Bielek P., Božík M., 2010: Soil and agriculture. Reflections on the future. Research Institute of Soil Science and Conservation, Bratislava, pp. 40.

4. Flood 2010, Žitava River. https://youtu.be/sMRiLpqh18I

5. Holičová M., 2013: Proposal of the local territorial system of ecological stability of the territory for the purposes of the Agricultural Paying Agency.
6. Húska D., Jurik L., 2000: Current problems of water management in the Eastern lowlands. Water management on Eastern lowlands, p. 120A, No. 1/ 200, District Environmental Office Michalovce.

7. https://sk.wikipedia.org/wiki/V\%C3\%BDchodosl ovensk $\% \mathrm{C} 3 \% \mathrm{~A} 1 \_\mathrm{n} \% \mathrm{C} 3 \% \mathrm{AD} \% \mathrm{C} 5 \%$ BEina

8. Jurik L., 2013: Water building. 2. ed. Nitra: Slovak University of Agriculture, pp. 196. ISBN 978-80-552-0963-0.

9. Kabina P., Jurík L., 1999: Perspective of drainage structures on the Eastern plains. In Proceedings: Land reclamation and water management at the turn of the millennium. Brno: Mendel University of Agriculture and Forestry, 129-133.

10. Kotorová D, Kováč, L., 2013: soil characteristics in the dry polder Besa. FOLIA GEOGRAPHICA Prešov 22.

11. Mateeul H. Memon A., M. Sher, M. Siddiqi, Jillani R., 2012: Techniques of Remote Sensing and GIS for Flood monitoring and damage assessment: A Case Study of Sindh province, Pakistan. The Egyptian Journal of Remote Sensing and Space Sciences 15, 135-141.

12. Magdalini P., 2015 : The complex relation of Land and Water in the Netherlands. In TU DELFT | EMU: Ttheories of urbanization, regionalization \& network. Prof. Stephen Read \& W. Zonneveld

13. Ministry of Agriculture 2011: Ministry of Agriculture and Rural Development 2011: Report on Agriculture and Food in the Slovak Republic for 2010, Ministry of Agriculture and Rural Development of the Slovak Republic.

14. Ministry of Environment 2011: Analysis of the level of flood protection Slovak Republic, including the state of implementation of flood warning and forecast system, the Ministry of Environment SR February 2011.

15. Satellite images 2016: Overview of satellite images: https://imagehunter.apollomapping.com/

16. SVP Banská Štiavnica. 2011: Modern floods in 2010, SVP Banská Štiavnica.

17. Technical university Zvolen 2011: http://mapy. tuzvo.sk/HOFM

18. VSN 2010: VSN flooded areas during the flood 06/06/2010 (ed.) LANDSAT. www.Data image Landsat

19. Zorád L., 2010: Simulation Of Flood Zones At Žitava River And Stream Hostiansky, Proceedings of the scientific work of $\mathrm{PhD}$ students and young scientists "Young Scientists 2010" UKF Nitra

20. WFD 2007/60 EU 2011: Implementation of Parliament and Council Directive 2007/60/EC of 23 October 2007 on the assessment and management of flood risks; Preliminary flood risk assessment in the sub-basin of the Bodrog. 